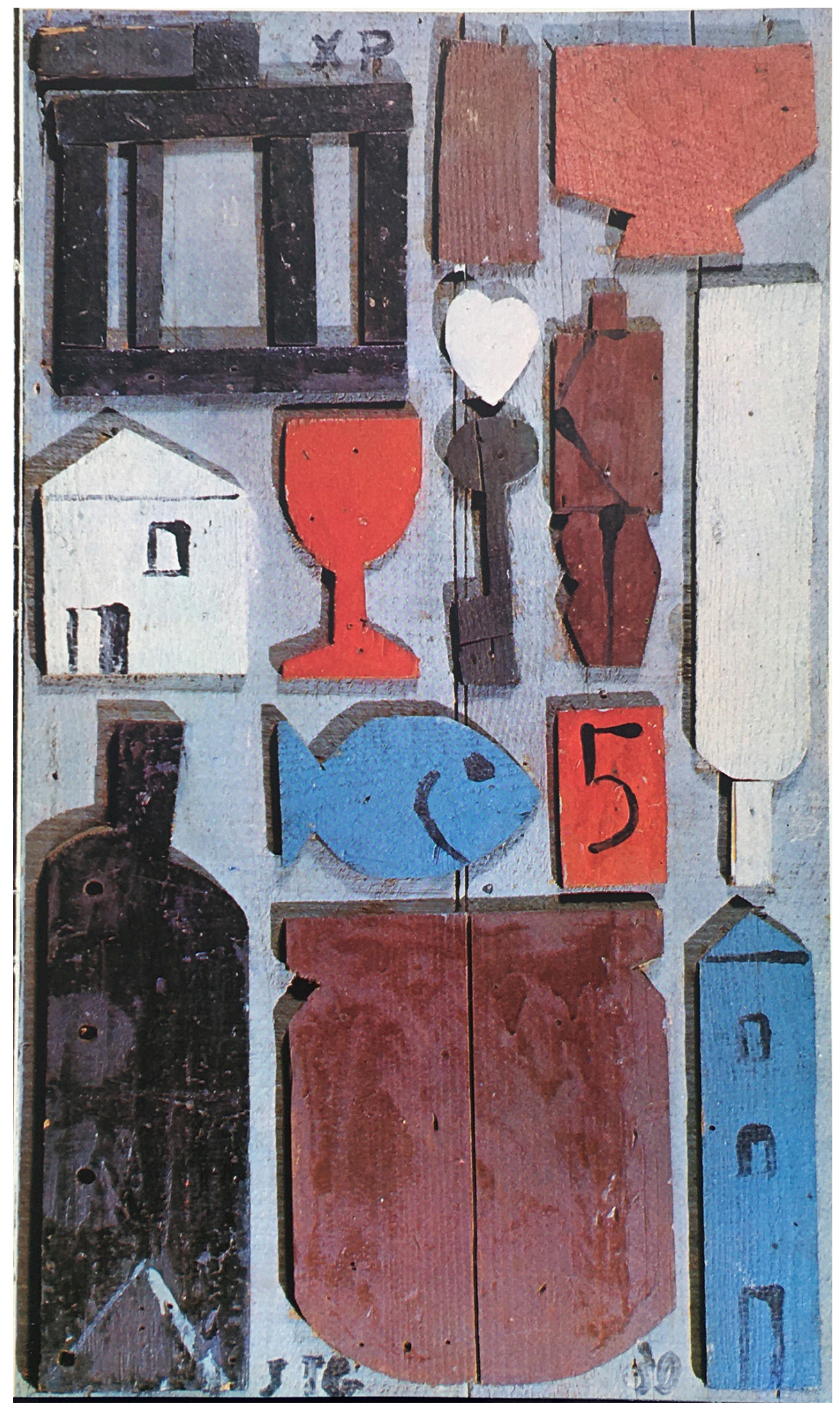

Fig. 1. Joaquín Torres García, Objetos superpuestos en colores, 1930. Realizada en París, madera policromada. Propiedad de la familia Torres García. 


\title{
Belleza eidética. Lo clásico y lo moderno en el platonismo de Joaquín Torres García
}

\author{
Eidetic Beauty: Classism and Modernity in Joaquín Torres García's Platonism
}

\author{
William Rey Ashfield \\ Universidad de la República, Montevideo, Uruguay \\ william@bmr.uy \\ https://orcid.org/0000-0002-3281-0273
}

\author{
Natalia Costa Rugnitz \\ Universidade Estadual de Campinas, Sáo Paulo, Brasil \\ natalia.costa.rugnitz@gmail.com \\ https://orcid.org/0000-0001-9361-0884
}

\section{Resumen}

La influencia del pensamiento de Platón en los escritos de Joaquín Torres García es, al presente, tan conocida como poco entendida. El abordaje crítico de esta relación en el plano de lo plástico es apenas identificable dentro del marco historiográfico. La incidencia de la idea platónica en las contradicciones epocales, particularmente en la relación de este artista con muchos movimientos de la vanguardia europea, empieza a ser materia tratada solo en las últimas décadas. Estos tres aspectos serán la materia del siguiente artículo, cuyo fin es profundizar en el platonismo torresgarciano desde el punto de vista teórico y práctico y ahondar en la complejidad pro-

\begin{abstract}
The influence of Plato's thought in Joaquin Torres Garcia's writings is, nowadays, as well-known as it is little-understood. A critical approach to the artistic element of this relationship is barely identifiable within the scope of historiography. The incidence of Platonic idealism in the epochal contradictions, particularly in associating Torres with certain movements of the European avant-garde, begun to be studied in recent decades only. These three aspects will be the subject of the following article, whose purpose is to think about Torresgarcian Platonism from both a theoretical and a practical point of view and to delve into the complexity of a period of great changes in art history: the first half
\end{abstract}

Cómo citar este trabajo / How to cite this paper:

Rey Ashfield, William, y Natalia Costa Rugnitz. "Belleza eidética. Lo clásico y lo moderno en el platonismo de Joaquín Torres García." Atrio. Revista de Historia del Arte, no. 25 (2019): 240-257.

(C) 2019 William Rey Ashfield y Natalia Costa Rugnitz. Este es un artículo de acceso abierto distribuido bajo los términos de la licencia Creative

Commons Attribution-NonCommercial-ShareAlike 4.0. International License (CC BY-NC-SA 4.0). 
pia de un tiempo de cambios en la historia del arte como lo fue la primera mitad del siglo XX.

Palabras clave: Platón; arte; idea; verdad; belleza; modernidad. of the XX century.

Keywords: Plato; art; idea; truth; beauty; modernity.

\footnotetext{
"Hay hombres que solo viven en el tiempo y otros en la eternidad... El que ve las cosas perennes, las cosas constantes, las grandes leyes que dominan el cosmos, ¿cómo podría fijarse en lo particular, en lo pasajero? No se fija; y entonces, en la cosa que pasa, no solo busca lo específico sino que, saltando sobre eso, no puede menos que buscar, en los medios plásticos, algo que con eso armonice; algo de orden también universal." Joaquín Torres García, Universalismo Constructivo.
}

\section{El arte como lugar de la idea platónica}

En su acepción clásica, el término belleza dista de referir solamente a una perfección de lo sensible que da ocasión para el goce. En ese filosofar atravesado de poesía que le es propio, Platón sostuvo que la belleza coincide, de alguna manera, con la verdad y el bien. Tal es la tríada clásica por antonomasia: bien, verdad y belleza. Según la sacerdotisa explica a Sócrates en El Banquete, la belleza es la fuente de la que mana el amor; eros es, en efecto, el deseo de unirse con el objeto bello, que se torna objeto amado, para procrear en y con él. Existe la belleza de los cuerpos y las formas, que tanto atrae a los jóvenes. Pero existe algo más allá: la belleza de las palabras. Aún más allá, existe la belleza del alma y finalmente, en la cumbre de la escalada erótica, existe la belleza en sí, desprovista de todo vínculo con la carne y con cualquier manifestación de la aisthesis. Ante semejante definición, y considerando además la reconocida cadencia clásica del pensamiento de Torres García, cabría esperar de buena gana que el sentido y el objetivo del arte estuviesen vinculados a la realización de la belleza. Nada más distante, sin embargo, de la posición torresgarciana, que reza categóricamente: "Hay que desechar la idea falsa de que el arte se propone la realización de la belleza (...) La belleza tiene que ser un resultado, nunca una finalidad."

La finalidad del arte tampoco puede ser descrita en función de la subjetividad del artista, por más rica y excepcional que esta sea. Si bien Torres entiende que el arte surge de una necesidad del creador, ${ }^{2}$ no es allí que radica su esencia: "El hombre que (...) prefiera vivir con sus instintos, será bien poca cosa como hombre y como artista." 3

Tampoco es el arte algo subordinado al devenir de la historia o la actualidad de la naturaleza. Así, ni la belleza, aún en su más alta acepción, ni la riqueza de naturaleza ni tampoco el devenir histórico o subjetivo del artista constituyen la esencia del arte.

Pero la reflexión torresgarciana no es solo demoledora. Al contrario, es posible encontrar en ella un conjunto de conceptos profundos y recurrentes, que se entrelazan dando lugar a una teoría que cabe llamar,

\footnotetext{
1. Joaquín Torres García, Universalismo Constructivo (Buenos Aires: Poseidón, 1944), 97

2. Cfr. por ejemplo Torres García, 113, 354.

3. Torres García, 230.
} 
por lo menos en cierto sentido, efectivamente filosófica. Uno de esos conceptos es el de lo universal; otro, el de verdad. "El arte, por su misma universalidad, tiene que darnos todo aquello que corresponda a tan elevado plano (...) Y deberíamos tener interés en realizar tal ideal, pues hasta responsabilidad tenemos, ya que nos damos cuenta de que, con ello, se afirmaría lo más grande (...) Dicho en una sola palabra: la Verdad.”4 Lo universal contiene o expresa una verdad, es decir un contenido estable e independiente de tiempo, lugar y cualquier otra particularidad circunstancial, y el arte debe "dar testimonio" o "constancia" de ello. Esa "verdad universal” — precisa Torres - es el núcleo de la noción platónica de idea. El sentido y la finalidad del arte son, por consiguiente, dar testimonio de las ideas platónicas. En Lo aparente y lo concreto en el Arte, se lee: "no vamos en busca de lo externo de las cosas, sino de la idea (en el sentido platónico)." $Y$ Y si acaso quedara alguna duda, considérese el siguiente pasaje: "Que Grecia es el punto de partida de nuestra cultura occidental, no hay que decirlo. Desde allí arranca un equilibrio que jamás se había logrado (...) y de esto Platón es testimonio. Este gran filósofo ya tuvo evidencia de lo que debía ser el arte (...) y que tantos siglos después (ahora) se comienza a realizar. Esta pintura (...) cuya total teoría exponemos, sería la pintura tal como Platón pudo concebirla."

Si Torres se presentase ante el tribunal de la Kallipolis y argumentara de esta manera, seguramente le sería permitido ejercer allí su arte.

Pero si bien existe una afinidad contundente y abiertamente asumida por Torres García en lo que hace a su propia axiología y la de Platón, su platonismo es un platonismo extraño. ¿Es posible pensar en una pintura capaz de dar constancia de la idea sin atentar contra la lógica interna del esquema filosófico de Platón? Se ha dicho que la "concepción platonizante" del arte de Torres es una especie de "platonismo de pintor" o "platonismo anómalo.” Según Juan Fló, en los escritos torresgarcianos:

Se produce el sincretismo entre una concepción platonizante, una fe religiosa y un sentimiento de participación en un universo regido por un orden que el arte realiza y comunica; estos fundamentos fueron siempre reacios a una síntesis satisfactoria. Esa oscura doctrina de Torres García se inicia probablemente con una fe quizá confesional y se reelabora y combina con un platonismo anómalo que se puede llamar "platonismo de pintor" porque le atribuye al pintor la capacidad de llegar a lo ideal desde la percepción del mundo. ${ }^{8}$

La tesis de que el arte es esencialmente un medio facilitador de la idea platónica parece ser, para Fló, una suerte de blasfemia contra el credo platónico. Esta acusación, sin embargo, no parece completamente justa. Fló sugiere que Torres se habría propuesto un "imposible platónico" al admitir la posibilidad de realizar, en la dimensión de lo material sensible (y más específicamente de lo plástico), algo que por definición pertenece a otro ámbito: justamente al ámbito de la idea o "mundo inteligible," utilizando el léxico del griego. Pero Torres no ha defendido que el arte deba "realizar" la idea, sino dar constancia de ella, traducirla, comunicarla de alguna manera. La diferencia, desde un punto de vista ontológico, es enorme. Por otro lado, si lo que Fló defiende es que Torres decae en un "platonismo de pintor" pues ha sido incapaz

4. Torres García, 610.

5. Torres García, 97, 211.

6. Joaquín Torres García, Lo aparente y lo concreto en el Arte (Montevideo: Centro Editor de América Latina, 1969 ), 26.

7. Alfredo Cáceres, Torres García: estudio psicológico y síntesis crítica (Montevideo: Imp. Ligu, 1941), 31.

8. Juan Fló, Imaginarios Prehispánicos en el Arte Uruguayo: 1870 - 1970 (Montevideo: MAPI, 2006). 


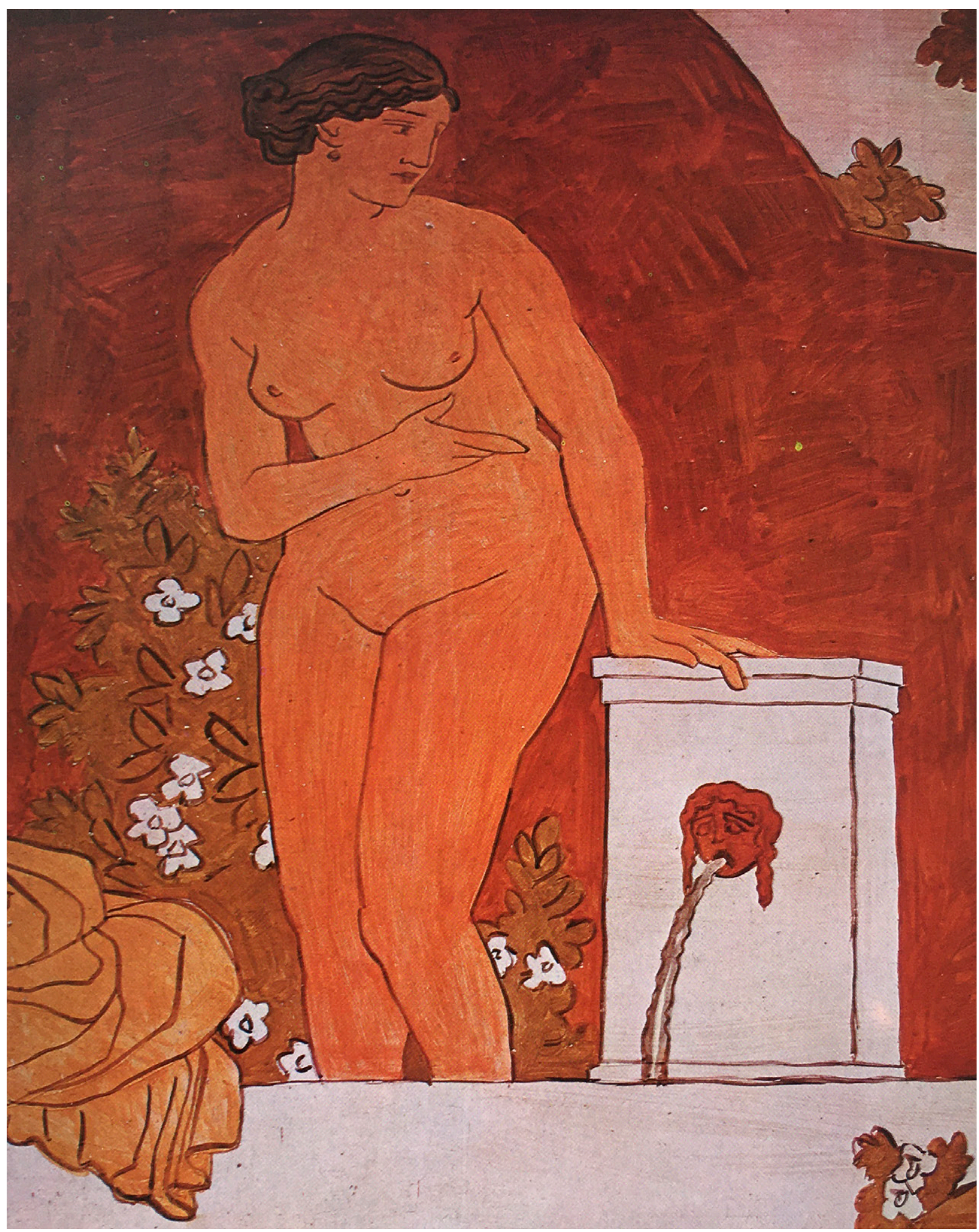

Fig. 2. Joaquín Torres García, detalle de frescos de su residencia "Mon Repòs", 1915 


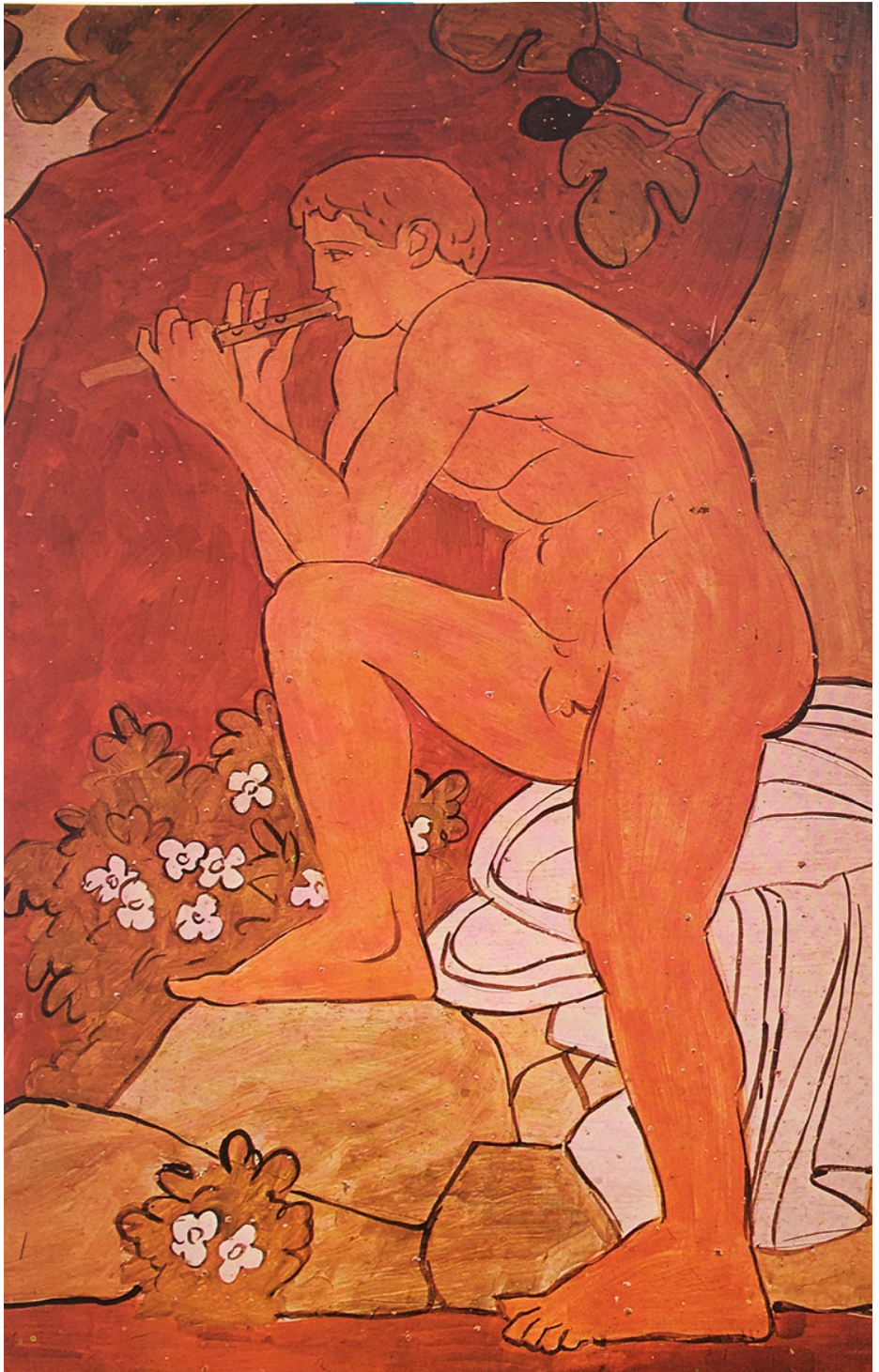

Fig. 3. Joaquín Torres García, detalle de frescos de su residencia "Mon Repòs", 1915 de comprender que la teoría platónica de las ideas implica una separación radical entre el mundo sensible y el inteligible, su posición es como mínimo problemática, en la medida en que se construye a partir de una interpretación del pensamiento del griego que, a pesar de muy extendida (especialmente en los círculos no especializados), no es del todo consistente.

Más allá de la inacabable polémica, hay buenas razones para creer que los "dos mundos" no son mutuamente excluyentes para Platón. De hecho, existe una interpretación alternativa que así lo concibe, apoyando su exégesis en la denominada "teoría de la participación." En el Timeo, por ejemplo, se lee que la materia es "la madre y el receptáculo de las Ideas (...) una especie invisible y amorfa que lo contiene todo y que participa, en cierto modo -muy difícil de comprender- de lo inteligible." La materia, ergo lo sensible y por lo tanto (de nuevo) lo plástico, participa de cierto modo misterioso del mundo de las ideas; siendo así, no resulta en absoluto imposible —de hecho, resulta antes bien probable e incluso necesarioque existan entidades en el mundo-de-lascosas que incorporen de alguna manera las ideas. Cuáles son esas entidades es un tema aparte, en el cual no podemos detenernos aquí. Anotemos simplemente que, si el diagnóstico de Fló se apoya en una distancia infranqueable entre los dos mundos, entonces constituye una crítica sospechosa, por no decir inapropiada. Esto no implica, sin embargo, que no haya realmente algo extraño en el platonismo torresgarciano.

Platón desconfiaba del arte. Consciente del poderoso influjo, principalmente de la poesía y el teatro, sobre la masa de los espectadores — una masa cuyos hábitos (ethos) y comportamiento estimaba motivados no por una inteligencia sobria y activa sino por una tendencia irracional a la imitación acrítica — tomó la drástica medida de la supervisión y la censura, exigiendo a los artistas que desearan mostrar su talento en los

9. Platón, Timeo, en Obra Completa (Madrid: Gredos, 1986-1988), 51a. 
palcos de la ciudad utópica que realizaran previamente una demostración de sus cualidades a los gobernantes ideales, quienes gracias a su claridad superior estarían en condiciones de detectar y excluir toda manifestación capaz de suscitar la perversidad moral en el público. Así, por ejemplo, en la "Ciudad Bella" de La República - la Kallipolis_, se tachan extensos pasajes de Homero que muestran a los dioses o a los héroes tomados por la ira, la lujuria, la cobardía, etc. En este contexto riguroso e intelectualista, el arte es curado de potenciales "elementos perniciosos" y, libre de ellos, asume una función educativa subordinada a la meta política: la justicia. Lejos de estar vinculado a la inteligencia y al logos, parece que para Platón el enorme poder del arte se debe en su estrecho vínculo con la sensibilidad. ¿De dónde proviene, entonces, la idea de Torres García de que su pintura sería la pintura tal como Platón pudo concebirla? ¿De dónde proviene, sobre todo, la tesis de que el arte puede $-\mathrm{y}$ debe- dar testimonio de la idea?

Tanto en la obra publicada como en los manuscritos que conserva el profuso archivo de la Fundación Joaquín Torres García en Montevideo se encuentran escasas referencias que revelen las lecturas predilectas del maestro. La ausencia, sin embargo, no es total. Si bien la cita al pie y la explicitación de las fuentes es una disciplina por lo general ajena a la tarea especulativa de Torres, en ocasiones ciertos autores son nombrados en el cuerpo del texto. Además de Platón, hay otra figura importante de la historia de la filosofía que nos interesa aquí particularmente y que es excepcionalmente invocada de modo explícito más de una vez: Arthur Schopenhauer. Schopenhauer, peculiar exponente del idealismo alemán y padre del pesimismo y del ateísmo filosófico occidental, desarrolla una concepción metafísica y principalmente una teoría del arte a la que Torres parece adherirse en varios puntos. Sobre ellos nos debruzaremos inmediatamente, pero antes cabe informar al lector sobre un hallazgo que justifica más aún la tarea. Entre los manuscritos que constituyen el archivo, junto a unos someros fragmentos de Horacio, Píndaro y Marco Aurelio, existe un volumen bajo el título El Mundo como Voluntad y Representación, es decir: la obra magna de Schopenhauer.

El índice de lo que se conoce como "Suplementos"10 se encuentra transcripto en el manuscrito en su totalidad por Torres, siendo posible reconocer una selección hecha por él, dado que algunos capítulos se encuentran subrayados con tinta roja. El contenido consiste en grandes párrafos de las secciones destacadas copiados literalmente. ${ }^{11}$ Los apuntes datan del año 1899, es decir, del período barcelonés de Torres. En su autobiografía, él mismo relata que estos años estuvieron signados por la lectura, el estudio y la meditación - es el momento del círculo de Sant Lluc, que según los registros poseía una soberbia biblioteca-. Quizá fue allí donde Torres entró en contacto con Schopenhauer. ${ }^{12}$ Independientemente de cuál haya sido el contexto del encuentro, la existencia del manuscrito es evidencia suficiente de que Torres conoció el pensamiento del maestro de Nietzsche tempranamente y que este le generó un interés singular. Prueba de ello es su empeño de copista, que resultó en un grueso volumen de más de 300 folios.

\footnotetext{
10. Los "Suplementos" constituyen el segundo tomo de El Mundo... y consisten en un comentario de sus principales tesis.

11. Se encuentran, también, otros tantos folios bajo los siguientes títulos: 1. "III. La representación independiente del principio de razón; la idea platónica; el objeto de arte" y 2. "IV. Afirmación y negación del deseo de vivificar la voluntad que ha llegado a la conciencia de sí misma." Ambas se corresponden, respectivamente al libro tercero de El Mundo... (que está dedicado al tema de la representación en exclusividad) y al cuarto (dedicado a la voluntad en exclusividad). También existe otro pequeño núcleo de escritos bajo el título "Ensayo sobre el libre albedrío," correspondiente a la obra homónima de Schopenhauer.

12. Resulta poco probable que El Mundo... se encontrara en la biblioteca de Sant Lluc, ya que este núcleo artístico e intelectual era católico y Schopenhauer es el padre del ateísmo moderno. Carlos Serra, responsable del archivo en la época de la investigación y gran conocedor del mismo (de hecho, a él se debe el hallazgo del manuscrito de Torres en cuestión que, sin su ayuda, seguramente hubiera sido inaccesible), ha sugerido la interesante hipótesis de que nuestro autor hubiera venido de alguna manera a saber sobre las ideas de Schopenhauer, quien por aquel entonces era bastante conocido en Europa, aunque no tanto como para encontrar sus obras a la venta en librerías de las accesibles para el entonces joven Torres García. La conjetura de Serra es que probablemente Torres haya encontrado El Mundo... en una biblioteca pública, y haya pasado un buen tiempo frecuentando dicho espacio con el fin de completar la transcripción.
} 
La así llamada "metafísica de lo bello" de Schopenhauer se expone en el Libro III de El Mundo... y consiste en una teoría estética general construida en función de ciertas premisas metafísicas y una epistemología de ellas derivada. Según Schopenhauer, la cosa en sí puede ser aprehendida por el sujeto a partir de la experiencia directa del propio cuerpo, y descrita como "voluntad de vida" — Wille zum Leben-13 o simplemente "voluntad." La voluntad se experimenta y se define como una fuerza, deseo o "ímpetu ciego" por venir a ser y mantenerse en la existencia. En su perenne esfuerzo por manifestarse, la voluntad se torna objeto, se "hace mundo." Este primer recuento de la metafísica schopenhaueriana se encuentra integralmente resumido en Universalismo Constructivo:

Kant llegó a la conclusión de que el noúmeno, la cosa en sí, era algo incognoscible. Pero luego, el que puede calificarse su discípulo, Arthur Schopenhauer, demostró, y bien ampliamente, que no solo era algo que podía conocerse, sino que además era algo que conocíamos íntimamente. Y que no era otra cosa que lo que podemos llamar voluntad de vivir. Fuere, pues, en los seres organizados (animales y plantas) o en la materia inerte (inanimada) se muestra igual deseo: una fuerza, cuya manifestación en diverso grado es el mundo fenoménico, la realidad. La voluntad de vivir es, pues, la esencia de la vida. ${ }^{14}$

Según Schopenhauer, desde un punto de vista cosmológico la voluntad se "hace mundo" progresivamente dando lugar a una gradación o jerarquía de entes: ${ }^{15}$ de modo inmediato, directo y originario se objetiva en la idea; ${ }^{16}$ luego, la idea decanta en los fenómenos sensibles. La idea, que el autor generalmente escribe en singular y mayúsculas, es la forma inmutable, imperecedera y que nunca deviene de todas las cosas que nacen, cambian y perecen: es "lo que únicamente podríamos decir que es (...) el modelo (...) el paradigma de todas las cosas." ${ }^{17}$ Schopenhauer se refiere, evidentemente y como él mismo lo reconoce, a la idea platónica. De un modo igualmente platónico, el alemán postula que el conocimiento de las cosas y de los fenómenos no debería confundirse, pues "el conocimiento [en sentido estricto] (...) solo puede ser de lo que siempre y en cualquier respecto (es decir en sí) existe:" "Las cosas de este mundo, que percibimos por los sentidos, no tienen un verdadero ser; devienen siempre, y no son nunca; solo tienen ser relativo (...) Por consiguiente, no pueden ser objeto de un conocimiento (episteme) propiamente dicho." 18

La realidad misma es, por lo tanto, jerárquicamente compuesta (el estatuto ontológico del fenómeno es inferior al de la idea, y todo se da en relación a la proximidad a la cosa en sí). También lo es el conocimiento: desde una perspectiva general, el conocimiento se da en términos de objeto y sujeto (pues implica un sujeto que conoce y un objeto que es conocido); desde un punto de vista específico, se despliega en modalidades inferiores y superiores. Por un lado está el conocimiento fenoménico, que tiene lugar en los moldes del tiempo, el espacio y la causalidad ${ }^{19} \mathrm{y}$, como tal, refiere a la experiencia sensible e individual del sujeto

\footnotetext{
13. La voluntad de vida schopenhaueriana se diferencia de la de poder nietzscheana, Esta última, que según gran parte de los comentadores se inspira en la primera, trae más la idea de dominio, de imposición, de afirmación sobre todo lo que ofrezca resistencia. La voluntad de vida, por su parte, reposa, comparada con la anterior, en un plano metafísico. Es la simple voluntad de aparecer, de manifestarse, de existir en el mundo fenoménico. Solo en un segundo momento, según el pensamiento de Schopenhauer, tiene lugar el enfrentamiento y la lucha.

14. Torres García, Universalismo Constructivo, 622.

15. En realidad, las jerarquías son dos: la de los reinos mineral, vegetal y animal (con su ápice en lo humano) por un lado, y la de voluntad-idea-fenómeno por el otro. Traemos en el presente contexto únicamente esta última, pues es ella la actuante en el contexto que nos ocupa.

16. Esto quiere decir que la voluntad — que es el en-sí del mundo, su esencia una y única— se objetiva inmediatamente en las ideas —siendo estas igualmente eternas, pero ya múltiples—, y luego, mediatamente (por mediación justamente de las ideas) en fenómenos — que además de multiplicidad especial implican finitud en el tiempo y dependencia causal-.

17. Arthur Schopenhauer, El Mundo como Voluntad y Representación (Buenos Aires: Editorial Biblioteca Nueva, 1927), 169.

18. Schopenhauer, 168-69

19. Tiempo, espacio y causalidad son, según Schopenhauer, figuras del principio de razón. La forma general de dicho principio es: "nada es sin una razón por la cual es" o "todo lo que es, es por una razón." Schopenhauer distingue cuatro modalidades en las que este principio se ramifica (o 4 tipos de causas): las que tienen que ver con 1. los fenómenos materiales empíricos, 2. los conceptos, 3. las partes del espacio y tiempo puro, y 4 . los sentimientos. Para cada uno de
} 
cognoscente y al aspecto particular del objeto conocido; por otro lado, está la idea universal y el conocimiento de la idea. El conocimiento de la idea es distinto al del fenómeno pues la idea misma es de una naturaleza otra: la idea está fuera del tiempo y el espacio y es independiente de la causalidad. Por este motivo, el conocimiento de la idea se mantiene ajeno a las condiciones de la experiencia del individuo: la idea no puede ser conocida por la sensibilidad individual, no puede ser conocida como fenómeno, no puede "ser vista." Si esto agotara la epistemología schopenhaueriana sería una catástrofe, pues el conocimiento en sentido estricto sería inalcanzable. Afortunadamente no es el caso: existe, para el alemán, una vía de acceso al conocimiento de la idea: la experiencia estética.

La experiencia estética puede tener lugar en dos esferas distintas: la de la naturaleza y la del arte. En ambas, un

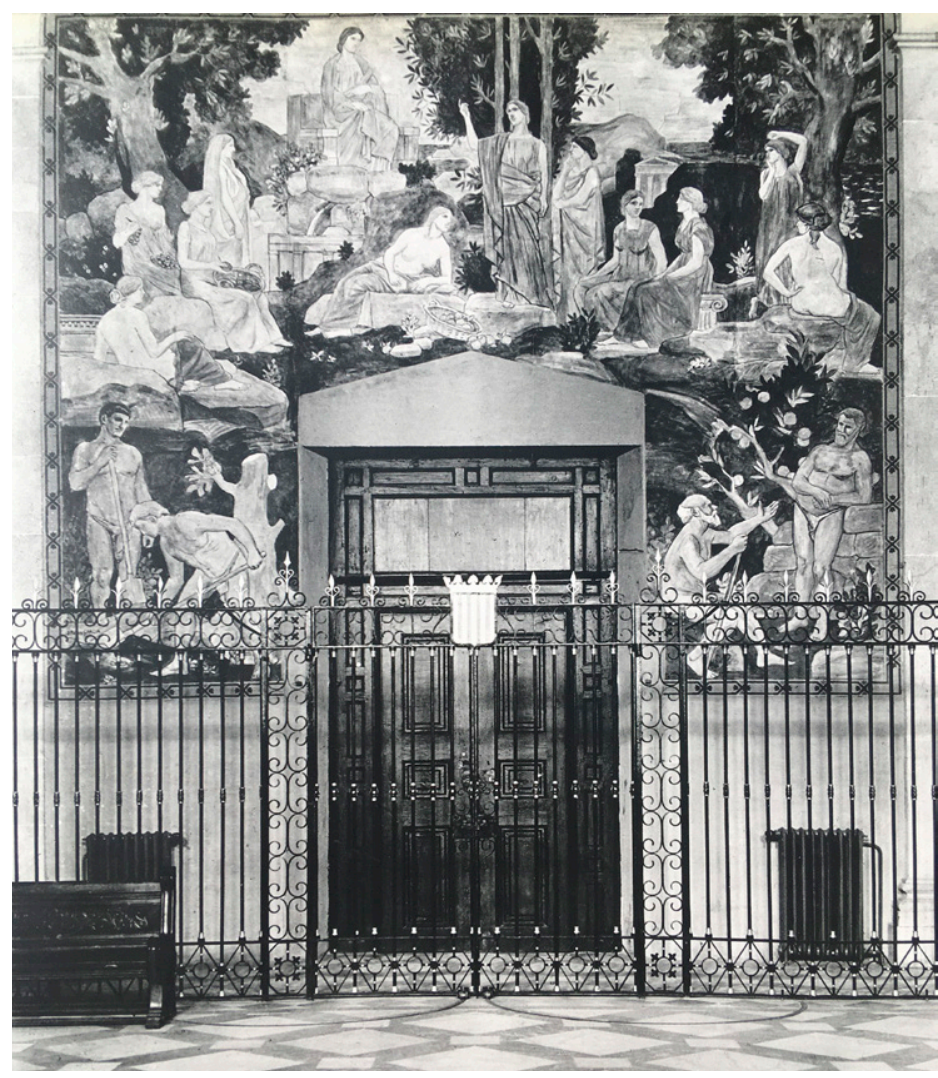

Fig. 4. Joaquín Torres García, fragmento del primer fresco del salón de San Jorge, 1913. Palacio de la Diputación de Barcelona. cambio radical afecta tanto al sujeto cognoscente como al objeto conocido: en lo que toca al objeto, este se expresa no ya en su particularidad fenoménica (esta manzana) sino en su carácter eidético o ideal (la manzana), es decir, de un modo ajeno al tiempo, el espacio y la causalidad; por su lado, el sujeto ingresa en el estado contemplativo: un estado en el cual la voluntad, esto es, el impulso natural a la acción, genera causas que produzcan efectos que se transformen a su vez en nuevas causas y así ad infinitum, se detiene momentáneamente. El que se relaciona desde esta posición con el mundo es llamado por Schopenhauer "puro sujeto de conocimiento," en contraste al "sujeto del querer," cuya experiencia está anclada a la experiencia del cuerpo y, por medio de ella, a la voluntad, el deseo y la sensibilidad. En la experiencia estética desaparece el fenómeno; en su lugar, emerge la idea. Junto con el fenómeno, el individuo mismo desaparece. Así, la experiencia estética es un encuentro desinteresado (el deseo se apaga) e impersonal (el individuo se anula) con lo que está más allá del fenómeno. Se trata de una circunstancia excepcional, en la que la mente humana escapa al mundo del devenir para adentrarse en un ámbito donde tiempo, espacio y causalidad no rigen: la dimensión de la eternidad, de la idea. ${ }^{20}$

los objetos de estas clases, el principio exige, necesaria y universalmente, una razón, causa o fundamento a partir de la cual exista. El conocimiento del mundo fenoménico -conocimiento "ordinario" o científico (que es el ordinario sistematizado)- es el sometido al principio de razón, es decir, el que queda contenido en el dónde, cuándo, porqué y para qué de la cosa. Sobre él se eleva el conocimiento no sujeto al principio de razón, es decir, el que dice respecto del "qué" de la cosa, o a la cosa en sí, independientemente de sus relaciones.

20. Dice Schopenhauer: "Como nosotros, en cuanto individuos, no tenemos otra clase de conocimiento que el regido por el principio de razón y esta forma excluye el conocimiento de las Ideas, es lo cierto que si es posible que nos elevemos del conocimiento de las cosas particulares al de las Ideas, ello sólo podrá suceder 


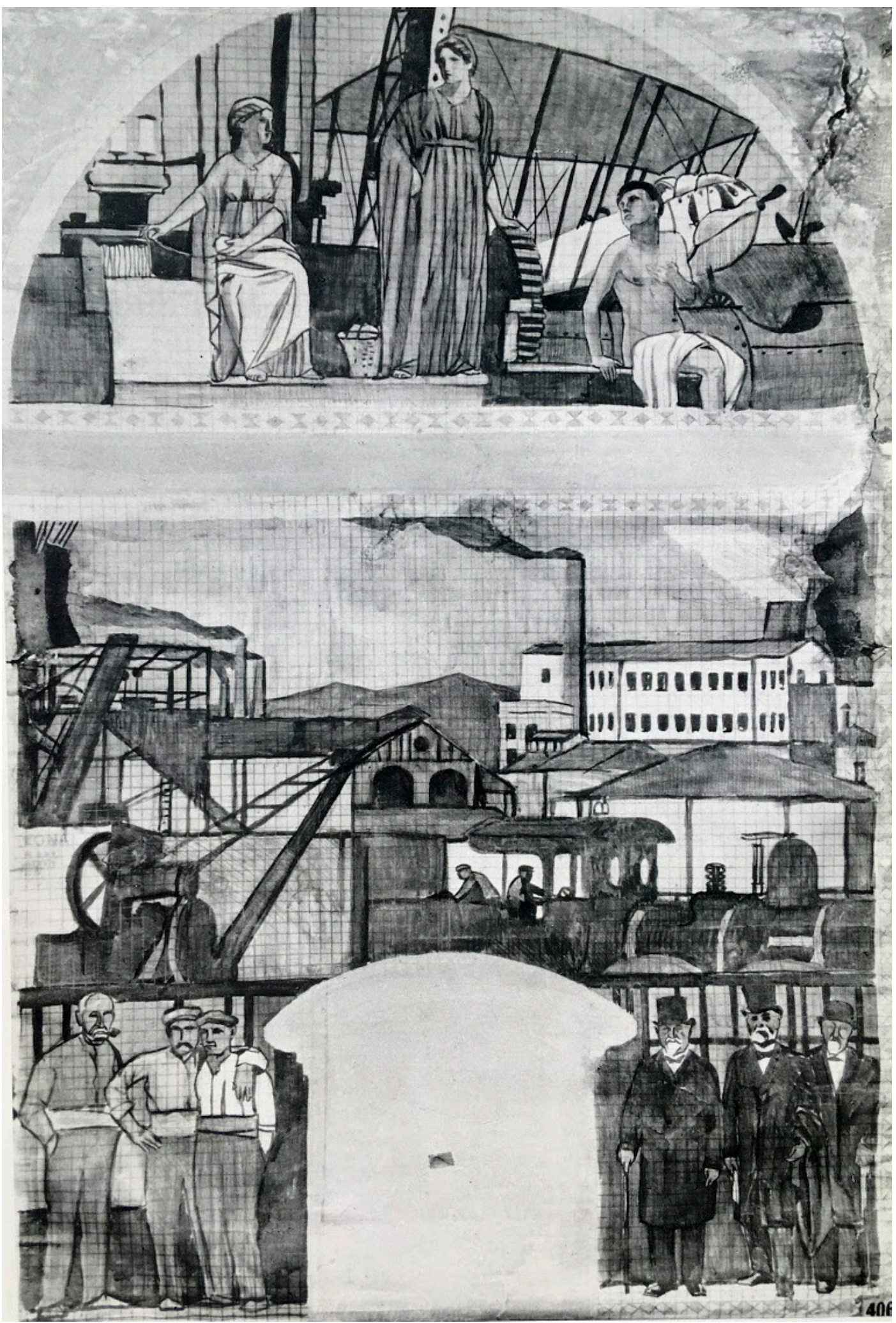

Fig. 5. Joaquín Torres García, boceto del quinto fresco realizado en el salón de San Jorge, 1913. Palacio de la Diputación de Barcelona. 


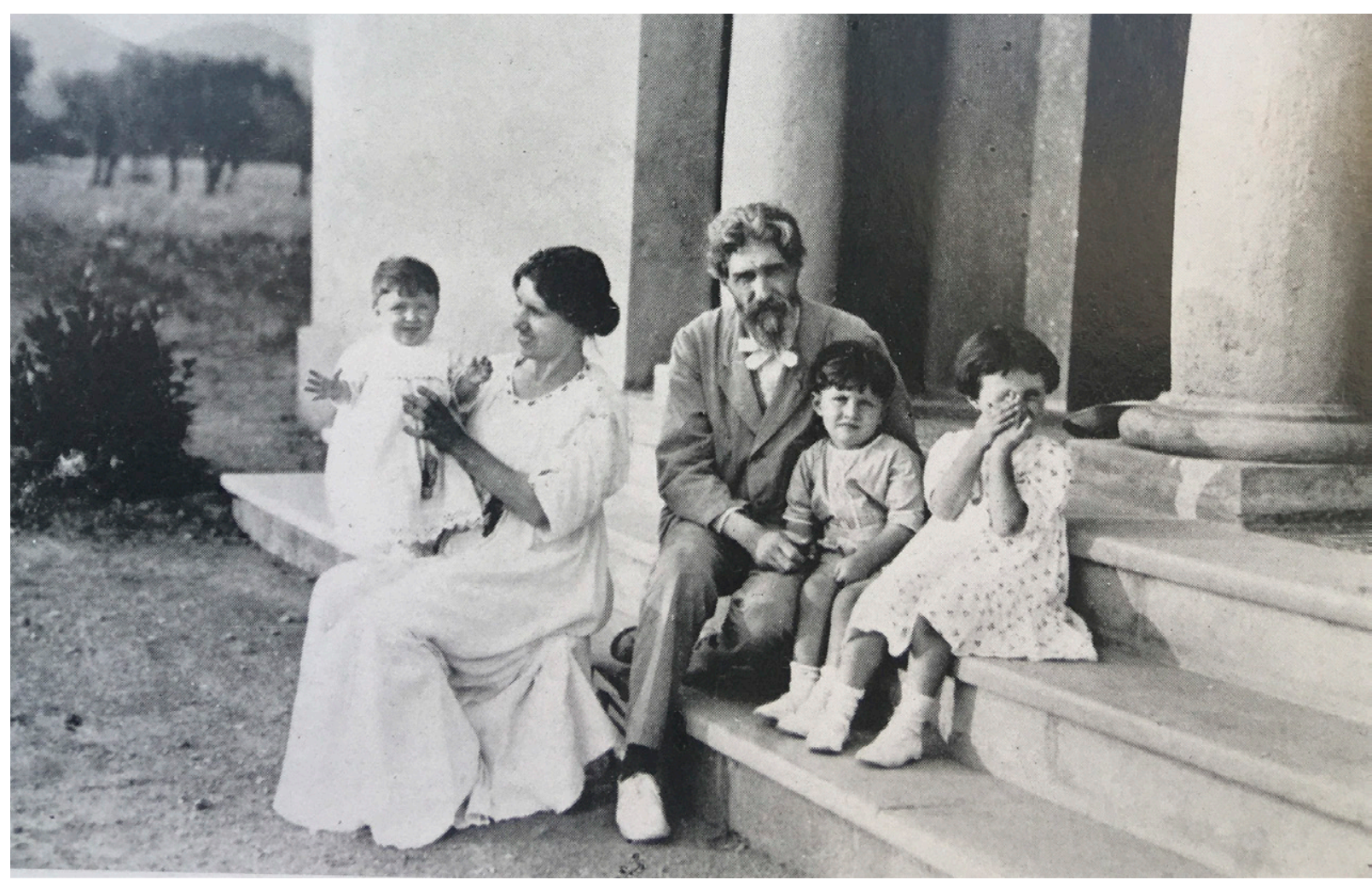

Fig. 6. La familia Torres García en "Mon Repòs".

Schopenhauer sostiene que todos los hombres poseen la capacidad de elevarse de la multiplicidad de fenómenos a la universalidad de idea; no todos, sin embargo, la poseen en el mismo grado: el genio (genie) la detenta máximamente y de manera innata. Como dijimos anteriormente, la experiencia estética puede ser suscitada sea por la naturaleza, sea por el arte. Concentrémonos en este último aspecto. Cuando el genio adquiere una técnica que le permita reproducir lo que su intuición le revela, se transforma entonces en artista. He aquí la concepción schopenhaueriana del arte: "Por medio de la obra de arte — dice el alemán— el genio nos comunica la intuición de la idea:" ${ }^{11}$ "[el artista] solo contempla la Idea y no la realidad; en su obra, solo reproduce aquella, aislándola y haciendo caso omiso de toda contingencia perturbadora (...) [y] nos hace ver el mundo por sus ojos. Lo propio del genio (...) es que su mirada descubre lo más esencial de las cosas, lo que estas son en sí y fuera de toda relación; pero la facultad de hacernos ver a nosotros, de prestarnos su mirada, esto es lo adquirido, la técnica del arte."22

"En toda obra de arte superior la idea de cada objeto, más que su realidad o particularismo, es lo esencial (...) él [el artista] ve en el color y en la forma la expresión de aquella idea," dice Torres García en Notes sobre Art; ${ }^{23}$ en Universalismo Constructivo, adiciona: "No concibo el solo vivir individual, sin más normas que

operándose en el sujeto un cambio análogo y correspondiente a aquel otro gran cambio que se opera en la naturaleza total del objeto, y mediante el cual el sujeto, en cuanto conoce una idea, ya no es individuo." Schopenhauer, El Mundo como Voluntad y Representación, 173.

21. Schopenhauer, 189

22. Schopenhauer, 190

23. Mario Gradowczyk, Utopía y Transgresión (Montevideo: Fundación TG, 2007), 23. 
las puramente instintivas de cada uno" ${ }^{24}$ y explicita, en referencia a la dimensión específica de lo artístico: "arte es saber hacer con reglas." ${ }^{25}$ No entraremos aquí en los detalles de la minuciosa reflexión torresgarciana sobre "la regla," baste señalar que existe, que es una reflexión sobre la técnica y que, siendo así, el mensaje de Torres adquiere un claro tinte schopenhaueriano. Si acaso la evidencia fuera aún insuficiente, considérese el siguiente pasaje:

Nada más ilusorio que la realidad: eso que se teje y desteje de continuo (...) formas, aspectos, movimiento, con todo el dramatismo inherente que trae ese eterno vibrar, ese eterno desear, que es, ante todo, deseo de permanecer. Por eso hubo que buscar aquello que de todo esto pueda quedar como algo inmutable, lo que es (...) entre esas contingencias (...) La vida no es lo que vemos y palpamos, sino algo más hondo. La existencia total de una cosa... está no en su existencia real y material, que será solo un aspecto, sino en la idea... Comprendemos, vemos, sentimos, que la IDEA TIENE VIDA PROPIA E INDEPENDIENTE, QUE LA IDEA ES [mayúsculas de Torres] (...) y de no admitirse esta vida independiente de la idea (...) tendríamos, en primer lugar, que todo es efecto de una causa anterior y no algo existente — como yo quiero, aunque no se comprenda- por sí mismo, y no se comprende porque todo lo vemos condicionado por el tiempo y el espacio; pero fuera de estas formas (...) tiene, por necesidad, que comprenderse de otra manera. ${ }^{26}$

He aquí condensados e implícitos — aunque no por eso menos presentes y actuantes - los grandes conceptos de Platón y de Schopenhauer o, para ser más precisos: he aquí, condensado y actuante, el núcleo duro de la metafísica platónica, atravesado por las categorías schopenhauerianas y asimilado orgánicamente en el centro del pensamiento de Joaquín Torres García.

\section{Idea y vanguardia}

Tanto en su plástica como en su pensamiento, Joaquín Torres García parece desmarcarse de lo que podríamos llamar la vocación inmanente de las vanguardias, es decir su sobrevaloración de lo mutable y su cuestionamiento a lo permanente en el plano estético. La idea de revolución campea en los discursos más radicales de los primeros años del siglo, manifiestos en la literatura panfletaria en general, aunque también en las prácticas artísticas y en muchos ejercicios plásticos, fundamentalmente del cubismo y el futurismo. La búsqueda de lo trascendente que intentan muchos artistas modernos les hace perder espacio visible, obligándolos, muchas veces, al refugio individual, ajeno a la organización de movimientos y tendencias. Torres García, en cambio, tiene una postura singular dentro de este contexto artístico, lo que no significa que por esto eluda la confrontación y la participación en grupos y exposiciones vanguardistas. Hay en él una ineludible aceptación de los tiempos en que vive. Pero también hay una singular búsqueda de constantes que puedan tomar forma en la producción del tiempo nuevo: la esencia y la permanencia son el foco de atención de Torres. Si bien es cierto que muchísimos artistas modernos y de vanguardia van tras lo permanente -incluso algunos (como Picasso) de un modo muy centrado en la innovación sistemática y la reformulación de lo hecho- la historiografía

24. Torres García, Universalismo Constructivo, 25

25. Torres García, 44.

26. Torres García, 154-57. Para Platón, las ideas son otra cosa que puras abstracciones: "son realidades activas y vivientes." Torres parece adherir también a esto. Lo real, que para él se encuentra contrapuesto a la idea, no implica que esta sea algo congelado, estático, sino algo animado y actuante: "la existencia, y vida (bien real), de la idea es un hecho," dice por ejemplo Torres (Torres García, 775). La obra de arte, en tanto "la idea y la cosa realizada [son o deben ser] una misma e idéntica cosa" (Torres García, 181), es por consiguiente algo que guarda las mismas condiciones: "tanta vida hay en una obra de arte como en un ser que se mueve, son lo mismo, en diverso plano" (Torres García, 629), o "Tiene, la pintura, vida propia... Vive, la pintura, a flor de tela" (Torres García, 731). 
y la crítica histórica han preferido "cargar las tintas" en la tendencia a lo inmanente, así como en una confirmación de que, para aquellos artistas, rige aquel postulado heraclitiano que sostiene que lo único constante es el cambio.

Si analizamos la producción de Torres, sin embargo, estos trazos pierden fuerza. En su lugar, gana protagonismo la tríada platónica bien-verdad-belleza, aunque con ciertos puntos de inflexión, que deben destacarse e identificarse.

La idea de lo clásico como lo permanente cortará transversalmente toda la obra de Torres. Lejos de entenderlo como una marca formal, lo clásico es precisamente una dimensión de lo eterno, de lo permanente $y$, por tanto, también de lo trascendente. Esta valoración clásica se descubre en Torres muy tempranamente, resultando muy ilustrativas las cartas que dirige a José E. Rodó luego de haber leído

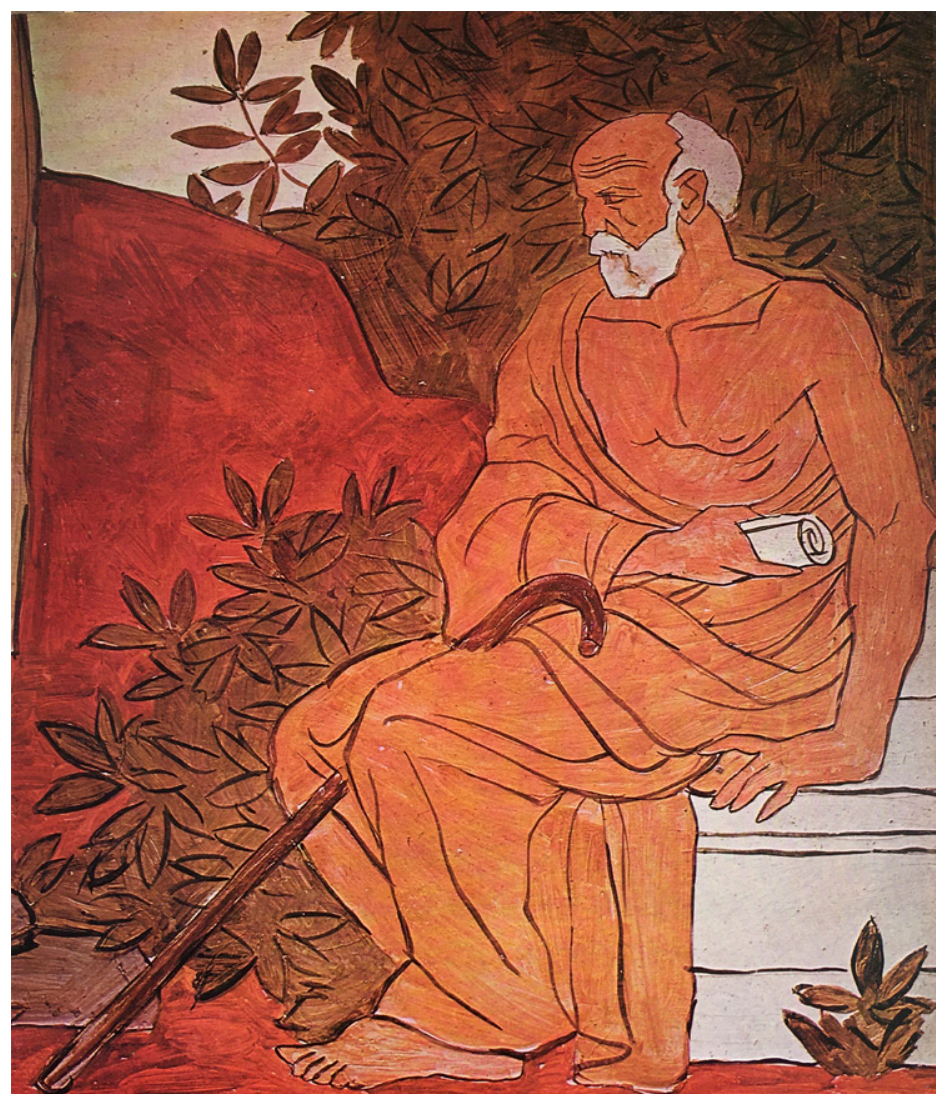

Fig. 7. Joaquín Torres García, detalle de frescos de su residencia "Mon Repòs", 1915. su ensayo Ariel, en los primeros ańos del siglo XX. ${ }^{27}$ También más tarde, cuando pinta en 1913 los frescos para el salón San Jorge del palacio de la Diputación en Barcelona, lo clásico surge como impronta dominante que no se reduce al tema, sino que se proyecta en la base abstracta de la estructura pictórica, en el conjunto de la composición, en el manejo del color (aunque este ya nada tenga que ver con la paleta propia de la experiencia neoclásica) y en la pérdida de cualquier rasgo accidental o realista.

Los cuerpos eluden la presencia de la sombra, que esclaviza y transforma el tiempo universal en un instante particular. Se trata de una construcción con vocación de verdad absoluta; una construcción que es moderna porque es de su tiempo, pero que no se reduce a él. En la representación del cuerpo humano hay también claros pathosformels de la tradición antigua, griega y romana, que parecen operar como verdaderas expresiones o representaciones de lo constante.

Pero para demostrar que en sus frescos no es el tema la base dominante de lo clásico, Torres García apela también a la representación de una modernización tecnológica, tal como lo podemos apreciar hoy en el boceto del quinto fresco, correspondiente al año 1918. 


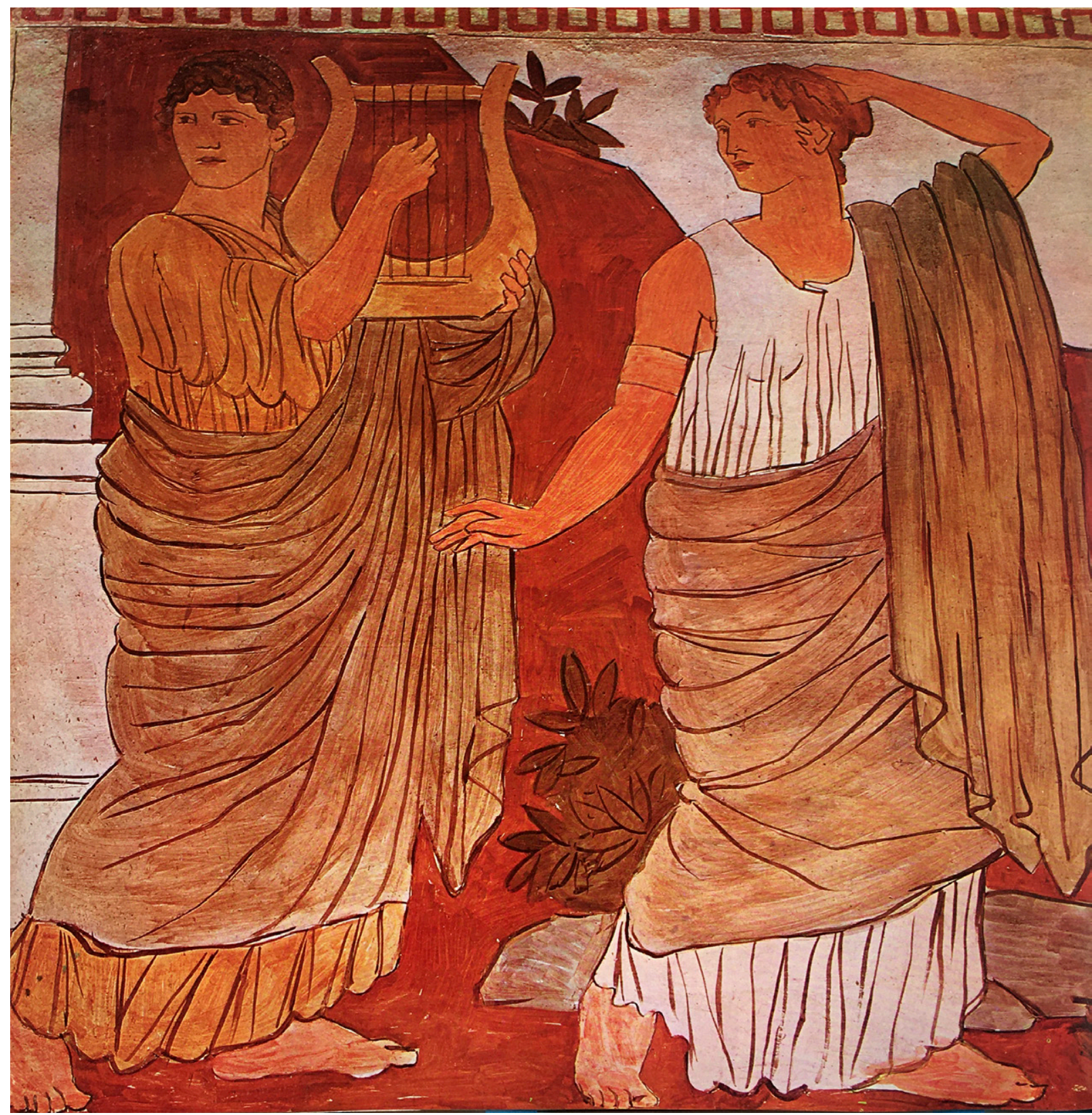

Fig. 8. Joaquín Torres García, detalle de frescos de su residencia "Mon Repòs", 1915

Será en su casa en Tarrasa, "Mon Repòs" — arquitectura que concibe y proyecta él mismo- donde se identifiquen ciertos cambios en el modo o tratamiento de lo clásico, aunque no una pérdida de interés en la búsqueda de la tríada antigua. La vivienda es un sitio para la reflexión, ajena al ruido citadino de Barcelona — una perfecta morada platónica— tal como él mismo nos dice en El descubrimiento de sí mismo: "Esa soledad moral, quiso mi orgullo hacerla material. Me fui al campo. Hice de mi casa una isla. Interpuse entre 
la ciudad y mi vivienda la cordillera que aún me separa. Desde ese momento todo lo esperé de mí mismo y todo lo busqué en mí mismo." 28

Torres se encuentra en un proceso de búsqueda e introspección afín a los postulados socráticos y al posible encuentro con una verdad trascendente, libre del mundanal suelo urbano. Es en esta vivienda donde Torres realiza una serie de paneles que se ubicarán en un interior estratégico: debajo de un lucernario que ocupa el eje de la planta edilicia, en clara proyección cosmogónica. Una axialidad que se potencia tanto en el sentido horizontal como en el vertical.

Aquí lo clásico no elude la modernidad de ciertas experiencias, como podrían ser las grandes masas de color, muy en paralelo con las experiencias desarrolladas entonces por Matisse. ${ }^{29}$ Sin embargo, la línea moldea aún la masa cromática, sin perder la importancia que tiene a lo largo de los diferentes momentos de la clasicidad histórica. La temática, en cambio, es rigurosamente clásica y en fuerte relación con la vida del hombre; se trata de cuatro paneles realizados al fresco sobre una lechada de cal, que exponen un tema frecuente en distintos tiempos del arte: las tres edades del hombre y una representación del amor y la belleza. Pero para una mayor relación con lo clásico - en tanto tradición- se invocan cuatro autores romanos: Juvenal, Cicerón, Virgilio, y Horacio. La obra en su conjunto exhala una dimensión cósmica: el hombre joven al oriente, bajo la máxima Vitam impendere
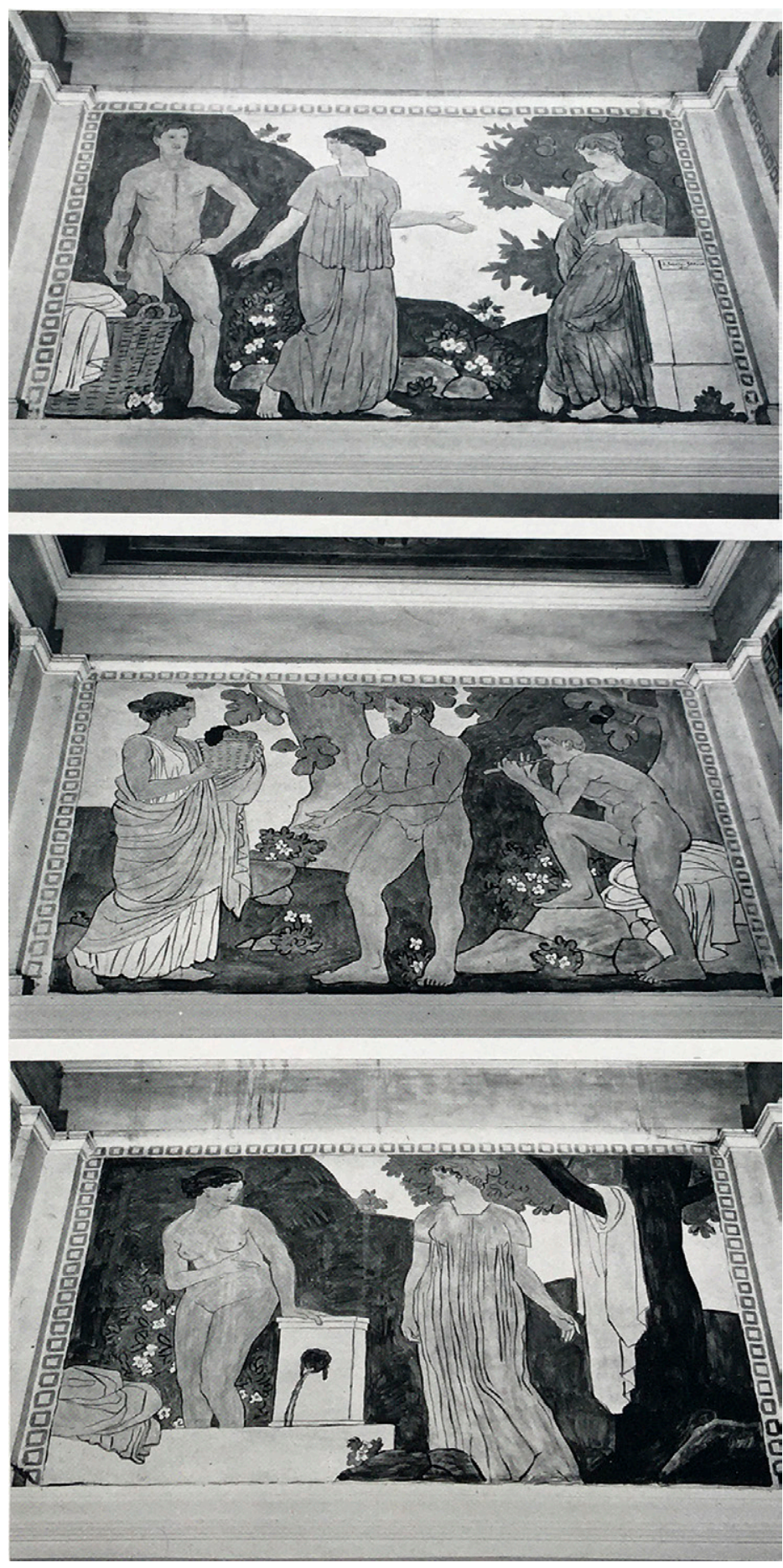

Fig. 9. Joaquín Torres García, frescos de su residencia "Mon Repòs". 


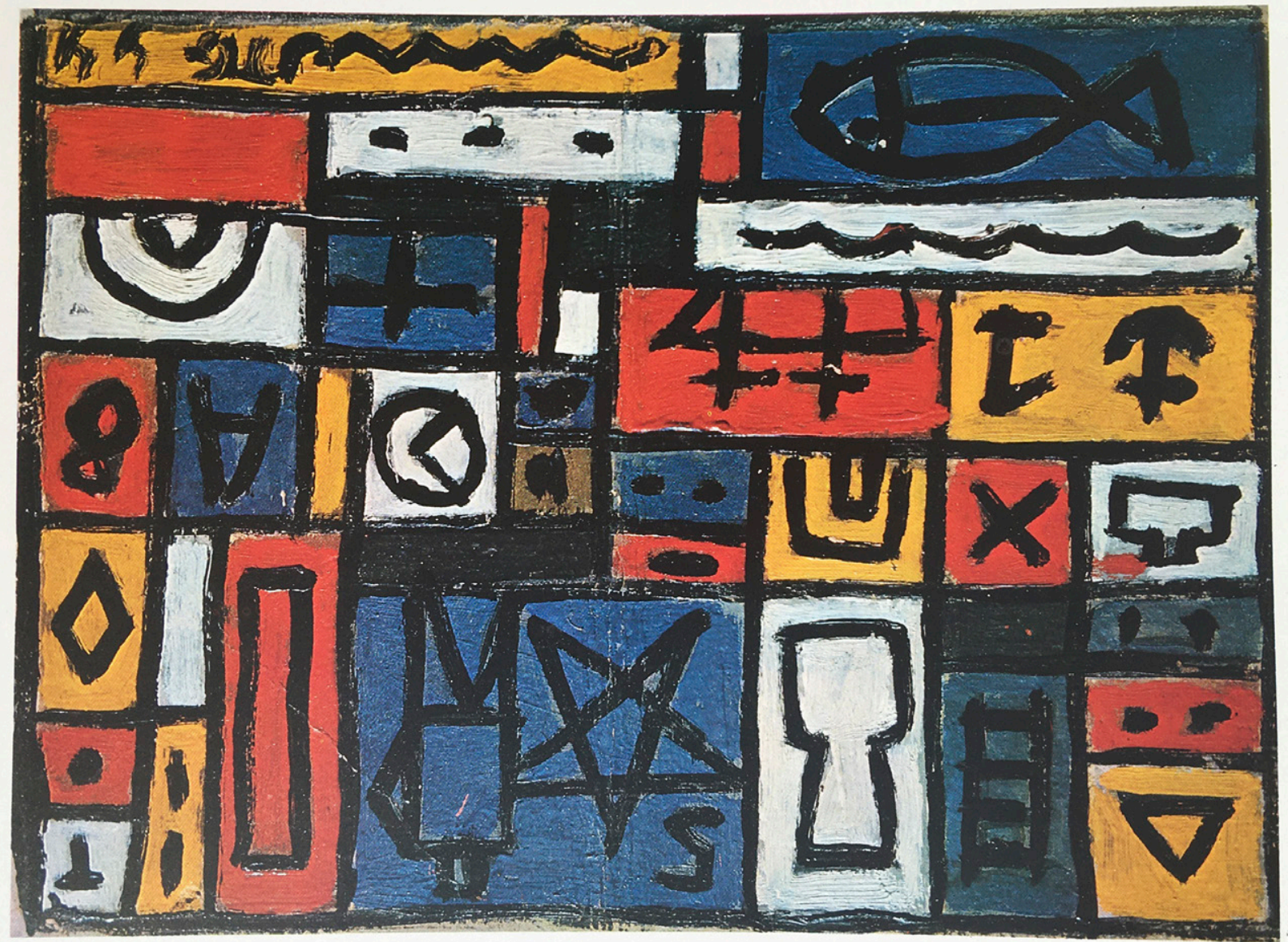

Fig. 10. Joaquín Torres García, Composición, 1944. Realizada en Montevideo, óleo sobre cartón. Colección Emilio Ellena, Santiago de Chile.

vero, de Juvenal; hacia el sur se ubica el hombre maduro acompañado de una frase de Virgilio, Melioribus Annis, lo cual nos habla de la plenitud; al poniente se ubica un panel que representa la belleza y el amor integrados, en el desnudo femenino que rotula con la frase de Cicerón, Omnia mecum porto; finalmente, el mural ubicado al norte refiere a la sabiduría, representada por un anciano que observa las figuras de las musas de la música y la danza —Euterpe y Terpsícore-, bajo la máxima horaciana Est modus in rebus.

Es interesante anotar que todas las sentencias parecen corresponder con la mirada platónica, muy especialmente la última, que ve en los objetos y en los hechos humanos un valor de medida.

En el pensamiento de Torres, el arte se conjuga con la densa metafísica del griego y de una función que trasciende la educativa. Para Torres, el valor del arte, si bien es en parte pedagógico, no se agota en esa utilidad: el arte es valioso en sí mismo, porque es soporte de la verdad y funciona también —y principalmente- como un dispositivo soteriológico que abre un acceso a instancias superiores del conocer y del ser. 
Torres García continuará produciendo a lo largo de toda su vida obras en alta consonancia con las hasta ahora citadas. Incluso en su última fase, en Montevideo, pueden apreciarse algunos murales bajo esta impronta, de moderada representación naturalista, ${ }^{30}$ fuerte intención clásica y con elementos de base abstracta, que buscan evitar lo particular o lo accidental en favor de la idea, aunque jamás de ideas alegóricas sino de ideas-verdad, en el sentido más platónico de lo eidético. Nuestro pintor ha registrado y asumido la visión de Schopenhauer, donde el artista es capaz de operar como traductor de lo eidético, razón que explicará todo su proceder plástico, en un continuum de investigaciones acerca de este tópico.

La experiencia constructivista será, en amplia medida, el ut supra de este recorrido. Esto no significará eludir los intercambios más variados e intensos con distintos repertorios iconográficos y morfológicos que hacen a la tradición mediterránea o a la experiencia formal del mundo precolombino americano.

El desembarco definitivo de Torres en Montevideo y la sistematización de su experiencia constructivista en ese ámbito servirá para afirmar, todavía más, su interés por lo eidético. Su amplia labor como ensayista y conferencista en el Uruguay de la época destacan, junto a su obra, esta vocación reflexiva por la captura y materialización plástica de la idea platónica; y es a esto que nos referimos con la expresión "belleza eidética." Quizá su salida del convulsionado mundo europeo pueda explicarse precisamente por la necesidad de evitar o superar aquel agotado mundo de la vanguardia heraclitiana, bastante obstinada en la búsqueda de nuevas formas, para volver a lo que está más allá de la circunstancia. En la capital uruguaya Torres García encuentra un espacio alterno, tranquilo y algo periférico, en el que produce, enseña y profundiza él mismo en la teoría y en la práctica esa nueva forma platónica - y schopenhaueriana - de concebir y ejercer la disciplina artística que es el Universalismo Constructivo.

Final

Asumimos entonces que en la obra de Torres García hay una experiencia plástica y teórica que hunde sus raíces en la época clásica, que se nutre de la modernidad y se transforma en el fundamento de una práctica artística definida y única. Platón está en el fondo de toda la producción torresgarciana y muy especialmente en aquel corpus ideo-formal que el artista denomina Universalismo Constructivo, en el cual la geometría y la proporción áurea — de clara raíz platónico-pitagórica — adquiere un protagonismo clave.

La dimensión moderna del Universalismo Constructivo es, paradójicamente, reactiva a muchos de los principios de una vanguardia extrema, algo jacobina, que no fue siempre eje esencial de lo moderno. En este sentido, la modernidad es un fenómeno más complejo y menos compacto de lo que se ha creído. Y la obra artística y escrita de Torres García así lo confirma.

Lo mismo podríamos decir del ideario platónico. El pensamiento del filósofo griego, continuamente filtrado por miradas particulares, ha enriquecido su ancestral estructura discursiva. La modernidad, a través de Schopenhauer, ha abierto nuevas lecturas de Platón, lecturas que en ocasiones han trascendido lo meramente especulativo para realizarse en otros ámbitos, en especial en el mundo de la plástica. En este sentido, Torres García es también factor de confirmación.

30. Es un buen ejemplo el mural ubicado en la unidad sanitaria del Sindicato Médico, en la calle Garibaldi, realizado durante su estadía montevideana. 


\section{Referencias}

Cáceres, Alfredo. Torres García: estudio psicológico y sintesis crítica. Montevideo: Imp. Ligu, 1941. Fló, Juan. Imaginarios Prehispánicos en el Arte Uruguayo: 1870-1970. Montevideo: MAPI, 2006.

Gradowczyk, Mario. Utopia y Transgresión. Montevideo: Fundación JTG, 2007.

Jardí, Enric. Joaquín Torres García. El descubrimiento de sí mismo. Barcelona: Ediciones Polígrafa S. A., 1973. Platón. Timeo. En Obra Completa. Madrid: Gredos, 1986-1988.

Rey Ashfield, William. "José Enrique Rodó, entre el monumento y la ciudad." Atrio. Revista de Historia del Arte, no. 18 (2012): 61-72.

Schopenhauer, Arthur. El Mundo como Voluntad y Representación. Buenos Aires: Editorial Biblioteca Nueva, 1927.

Torres García, Joaquín. Universalismo Constructivo. Buenos Aires: Poseidón, 1944.

---. Lo aparente y lo concreto en el Arte. Montevideo: Centro Editor de América Latina, 1969. 